\title{
A color aftereffect contingent on complex pattern features
}

\author{
J. CAVILL and J. O. ROBINSON \\ University College, Cathays Park, Cardiff, Wales
}

\begin{abstract}
It was shown that a McCollough-type color aftereffect could be induced using a pair of patterns each of which contained lines of many orientations (radial lines and concentric circles). That is, the two patterns appear to be color adapted independently. The effect could simply be a new version of the McCollough effect facilitated by a tendency to fixate the centers of the patterns. Also, the size features of the displays could be used as the basis of a spatial frequency analyzer explanation. Experimental data were used to test both of these suggestions, but very little support was found for either. It was therefore suggested that the major basis of the effect was the color adaptation of "curvature analyzers."
\end{abstract}

Since McCollough's paper (1965 describing what has now become known as the McCollough effect, a great deal of further work has been carried out. McCollough found that, after a subject had viewed orange horizontal alternating with blue vertical lines (or the reverse color-pattern pairs), the complementary color aftereffect seen on acromatic test lines was dependent on their orientation. McCollough suggested that this stimulus-contingent complementary color aftereffect was caused by the independent color adaptation of two sets of orientation receptors. This is a model which has been generalized to account for stimulus-contingent aftereffects which have since been discovered, for example. the complementary color aftereffect contingent on the direction of motion (up or down of a set of horizontal lines (Stromeyer \& Mansfield, 1970) and the color-contingent tilt aftereffect (Held \& Shattuck. 1971).

McCollough's explanation has been criticized. Harris and Gibson (1968) developed an alternative explanation based on simple afterimages. If subjects tend to fixate particular geometrically equivalent areas of the inspection patterns, then the retinal adaptation will be patterned in such a way that the two aftereffect colors could be differentially elicited by the two test patterns. They found, however, that when each pattern was presented in one of two positions randomly. such that the resulting retinal adaptation would be homogeneous, the effect could still be set up. They pointed out that this result does not force one to accept the orientation receptor hypothesis and suggested an alternative dipole hypothesis. However, dipoles may be considered merely as orientation receptors which are retinally defined. The dipole hypothesis may be elaborated to account for other stimulus-contingent aftereffects, but if this is done it becomes successively more cumbersome. Moreover, the reported long duration of some of the contingent aftereffects (Stromeyer \& Mansfield, 1970) suggests that more than retinal units are involved.
Murch (1972) claimed that McCollough's model was invalid after showing that a size aftereffect transferred to a nonstimulated eye whereas a color aftereffect did not. The situation here appears to be complex (Mackay \& Mackay, 1973), and Murch's result could contain significant information on the manner in which color information is coded or the sites at which adaptation takes place. In either case, McCollough's model may be seen as too simple rather than invalid.

There seem to be no published experimental results which seriously undermine McCollough's suggestion. However. a type of display which ought to be embarrassing for the McCollough position if it can elicit contingent aftereffects would be one in which both the adaptation and test figures contained many orientations. A study using such displays is reported here.

\section{EXPERIMENT I}

This experiment used displays consisting of radial lines or concentric circles in an attempt to establish a stimulus-contingent color aftereffect.

\section{Method}

Apparatus. A set of four high-contrast black-and-white patterned slides, comprising two adaptation patterns (which could be paired with color filters) and two test patterns, was used. The adaptation patterns were a set of concentric circles and a set of radial lines (Figure 1). The test patterns each contained areas cortesponding to both of the adaptation patterns (Figure 1). The two color filters used were Kodak Wratten gelatin filters. No. 25 (red) and No. 58 (green). The slides were projected by means of a standard $100-\mathrm{W}$ halogen lamp projector onto a white screen. The image of the patterns was about $1 \mathrm{~m}$ in diam. and the subjects viewed from a distance of about $2.5 \mathrm{~m}$.

Subjects. The subjects were six 17-year-old girls. All subjects took part in the experiment with whatever optical correction they usually wore and none was color blind.

Procedure. In order that the subjects could be tested as a group. responses were elicited by questionnaire as follows: 


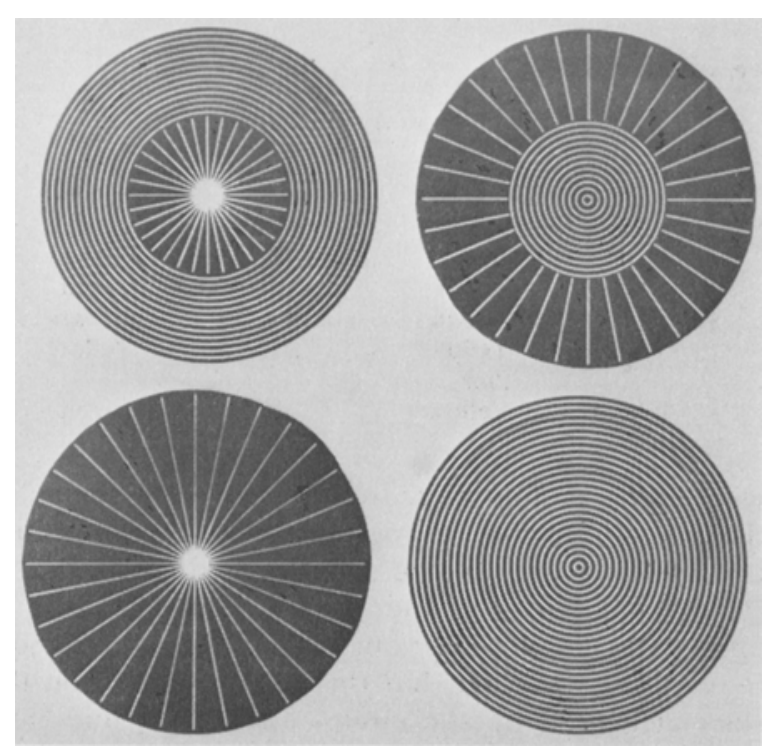

Figure 1. The four displays used in Experiment I. The two adaptation patterns (above) were paired with color filters (see text).

1. Do the white areas appear to be tinged with any color?
(a) the circles
yes (color is .....) / no
(b) the radial lines
yes (color is .... $) /$ no

2. If you were only allowed to answer 'blue' or 'pink' how would you describe
(a) the circles?
blue/pink
(b) the radial lines?
blue/pink

The stages in the experiment were, thus: (a) Presentation of the two test slides, each followed by the questionnaire. (b) Presentation of the adaptation slides (red radials and green concentric circles) alternately for periods of $15 \mathrm{sec}$ each for a total of $5 \mathrm{~min}$. (c) Presentation of the two test slides. each followed by the questionnaire.

\section{Results}

The forced choice data are presented in Table 1. The responses before adaptation show a random distribution (one-tailed binomial test, $\mathrm{p}=.58$ ). The responses after adaptation, however, show considerable agreenent (binomial test. $p=.002$ ).

Although the subjects appear to have had some difficulty in responding to the free choice questions (show'n in Table 2). evidence for the hypothesized effect may still be seen. A total of nine color words were used before adaptation; after adaptation, 17 color words were used. As can be seen in Table 2, the increased frequency of color words also contains a trend towards the agreement which was shown in the forced choice data. This trend may be taken as further evidence. which is difticult to test validly, that the hypothesized effect occurred.

\section{Discussion}

The forced choice data shows a highly significant result which supports the idea that it is possible to induce a stimulus-contingent, complementary color aftereffect for two patterns, each of which contain lines of many orientations.

One explanation of this result could be that by analogy with the McCollough effect curvature is analyzed as a feature of visual perception. The patterns are thus analyzed independently at the level of color adaptation because only one pattern involves curvature. If one assumes, however, that subjects tended to fixate the center of the adaptation patterns, then one can explain the effect by means of orientation analyzers and without recourse to curvature analyzers, since, in this case, every point of the visual field is stimulated by lines in the two patterns which are orthogonal. This has already been shown to be a sufficient condition to establish a stimulus-contingent complementary color aftereffect (McCollough, 1965).

A second experiment examined the role of fixation.

\section{EXPERIMENT II}

The aim of this second experiment was to present a test stimulus which would elicit a color aftereffect only if fixation on the center of the adaptation patterns had given rise to adaptation of orientation analyzers. Such a test stimulus takes the form of a plain grid covered by a cross-shaped mask (Figure 2). Depending on the orientation of the plain grid, subjects who have been fixating the center of the adaptation patterns and who tixate the center of the cross should report a color aftereffect of one color on the areas of the cross containing the long lines and the other on the areas containing the short lines. Subjects who did not fixate the center of the adaptation patterns should see little or no color aftereffect.

This experiment also replicated Experiment 1 with several improvements in design but using the same displays.

Table 1

The Forced Choice Data for the First Experiment

\begin{tabular}{|c|c|c|c|c|c|c|c|c|}
\hline \multirow[b]{4}{*}{ Subject } & \multicolumn{4}{|c|}{$\begin{array}{c}\text { Responses Before } \\
\text { Adaptation }\end{array}$} & \multicolumn{4}{|c|}{$\begin{array}{c}\text { Responses After } \\
\text { Adaptation }\end{array}$} \\
\hline & \multicolumn{4}{|c|}{ Test Pattern } & \multicolumn{4}{|c|}{ Test Pattern } \\
\hline & \multicolumn{2}{|c|}{1} & \multicolumn{2}{|c|}{2} & \multicolumn{2}{|c|}{1} & \multicolumn{2}{|c|}{2} \\
\hline & $\mathrm{C}$ & $\mathbf{R}$ & $\mathrm{C}$ & $\mathbf{R}$ & $\mathrm{C}$ & $\mathbf{R}$ & $\mathrm{C}$ & $\mathbf{R}$ \\
\hline 1 & 0 & 1 & 0 & 0 & 1 & 1 & 1 & 1 \\
\hline 2 & 1 & 0 & 1 & 0 & 1 & 1 & 1 & 1 \\
\hline 3 & 1 & 0 & 1 & 1 & 1 & 1 & 1 & 1 \\
\hline 4 & 1 & 0 & 1 & 0 & 1 & 1 & 1 & 0 \\
\hline 5 & 0 & 1 & 0 & 1 & 1 & 1 & 0 & 0 \\
\hline 6 & 0 & 1 & & 1 & 1 & 0 & & 1 \\
\hline Totals & \multicolumn{2}{|c|}{6} & \multicolumn{2}{|c|}{6} & \multicolumn{2}{|c|}{11} & \multicolumn{2}{|c|}{8} \\
\hline \multirow{2}{*}{\multicolumn{2}{|c|}{$\begin{array}{l}\text { One-Tailed } \\
\text { Binomial } \\
\text { Probabilities }\end{array}$}} & .61 & \multicolumn{2}{|c|}{.61} & \multicolumn{2}{|c|}{.003} & \multicolumn{2}{|c|}{.19} \\
\hline & & & & & & & & \\
\hline
\end{tabular}

Note-Responses are shown either as appropriate (1) or inappropriate (0) to the hypothesized aftereffect. 
Table 2

The Free Choice Data for Experiment I

\begin{tabular}{|c|c|c|c|c|c|c|c|c|}
\hline \multirow[b]{3}{*}{ Subject } & \multicolumn{4}{|c|}{ Responses Hefore Adaptation } & \multicolumn{4}{|c|}{ Responses After Adaptation } \\
\hline & \multicolumn{2}{|c|}{ Test Pattern I } & \multicolumn{2}{|c|}{ Test Pattern 2} & \multicolumn{2}{|c|}{ Test Pattern 1} & \multicolumn{2}{|c|}{ Test Puttern 2} \\
\hline & C & $\mathbf{R}$ & $\mathrm{C}$ & $\mathbf{R}$ & $\mathrm{C}$ & $\mathbf{R}$ & C & $\mathbf{R}$ \\
\hline 1 & \multirow[t]{3}{*}{ Bluc } & \multicolumn{3}{|c|}{ Blue } & \multicolumn{2}{|l|}{ Pink } & Red & Green \\
\hline 2 & & & & & Red & Green & Pink & Green \\
\hline 3 & & Brown & & Brown & & Brown & & Brown \\
\hline 4 & Brown & Brown & & Yellow & Yellow & Yellow & Brown & Yellow \\
\hline 5 & & & & & & Pink & & \\
\hline 6 & & & Blue & Blue & Green & Yellow & & Green \\
\hline
\end{tabular}

\section{Method}

Subjects. The subjects used were eight undergraduates. All were ingert abuut 20 years. All wore lheir usual spotical correction and unete was color blind.

Apparatus. The apparatus comsisted of the four slides used in the lirst experiment and tuo line gratings. These latter were a horicontal and vertical grating of straight and parallel lines. There was very little difterence in the spatial frequency of these gratings and that of the concentric circles (ratio between spatial frequencies

1.1. ratto betueen line widths 1.4). These were paired as tes figures with a cross-shaped mask (Figure 2). This reduction of the patterns in the test situation to the form of a cross enabled the experimenter more easily to refer to the ditferent parts of the displaty where a color altereffect might oxceur. A fixation spot could be placed at the center of the cross.

the methed of display of the patterns was as used in the first experiment.

Procedure. Fach subject was tested individually. As belort. the subjects made written responses to the questionnaire. The forced choices used on this occasion were "green" and "red." following Murch's $(1 \%(9)$ data. which suggest that these were preterred by the subjects in a free response situation using similar adaptation colors.

The subjects were pretested on the forced chojce question of the questionnaire. having viewed the test patterns of circles and radial lines. They were then randomly assigned to two groups, which were shown oppexite pattern color pairs ti.e.. red concentric circies. green radial lines, and vice versa).

louring the adaptation period (which again lasted $5 \mathrm{~min}$ ), the subjects vicwed the colored adaptation patterns alternately for periods of 15 sec each. The adaptation period was followed by a 5-min rest period to allow any "buildup" of the effect to (xecur. (Such "buildup" has been reported by Mayhew and Anstis, 1972.)

Following the rest period. the subjex:s were lirst tested on the eross-shaped lined stimuli. For both horieontal and vertical bars of each cruss. they first answered the questionnaire (adapled to reler Io the cross-shaped pattern) with no fixation instructions and no fixation spot. These obstryations were then repeated with the fixation spot in plase and an instruction to fixate it.

The subjects then viewed the concentric cireles and radial lines test patterus. Again. they responded to the questionnate for each of the two areas in the two patterns. Finally. all the above cot stimuli were presented in reverse order and subjects checked their responses. This was a rough check on the possibility that the alfereffects were in the process of building up during the tirst set of observations, thus giving a greater effect in the later observations.

\section{Results}

The preadaptation data showed no significant trends. By considering the color-pattern pairs viewed by each subject, the forced choice responses may be catcgorized as appropriate or inappropriate to the orientation model predictions. One subject reported clearly seeing aftereffect colors on the cross-shaped stimuli. She also reported that the colors "flipped" as might the perspective in a Necker cube. Obviously, these reports cannot be scored as suggested above, so this subject's results are not considered in the main statistical analysis but are discussed fully below.

After categorizing the forced choice data as appropriate or inappropriate to the orientation model predictions, it is clear that there is agreement on the colors attributed to the circles and radial lines test stimuli but no agreement on those attributed to the cross-shaped stimuli (lable 3 ). The cross-shaped stimuli elicited 29 appropriate responses in a total of 56 (8 responses for each subject). The circles and radial lines test stimuli elicited 24 appropriate responses in a lotal of $28 / \mathrm{p}(29,56)=.45 ; \mathrm{p}(24,28)=$ (x) 016 . one tailed binomial test]. When the two lixation conditions were separated, neither showed a significant proportion of appropriate responses, Thus, even with the help of a fixation spot, fixation did not become an effective variable. The data were therefore pooled over the two fixation conditions.

Agreement across subjects in the free choice data is also found only for the circles and radial lines test stimuli. These stimuli not only elicited more color words but they were often the expected ones. The range of color words used was extremely limited and all were easily classitied (Table 3). Of the 13 color words (in 56 responses) elicited by the cross-shaped stimuli, only 7 were appropriate to the model. Of the 17 color words (in 28 responses) elicited by the circles and radial lines test stimuli, 16 were appropriate Ip $(7,1,3)=.29 ; p(1,17)=.(\times 003$, onc-tailed binomial test. Again. the data were pooled over the two fixation conditions.

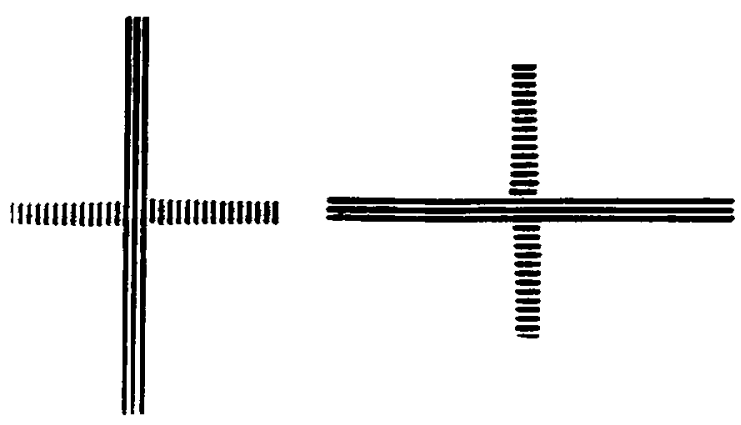

ligure 2. The two cross-shaped lest stimuli. 
Table 3

The Data of the Second Experiment

\begin{tabular}{|c|c|c|c|c|c|c|}
\hline & & \multirow[b]{2}{*}{$\begin{array}{l}\text { No } \\
\text { Color }\end{array}$} & \multicolumn{2}{|c|}{ Free Choice Data } & \multicolumn{2}{|c|}{ Forced Choice Data } \\
\hline & & & $\begin{array}{c}\text { Circles } \\
\text { Expected } \\
\text { Color } \\
\end{array}$ & $\begin{array}{c}\text { Radial Linos } \\
\text { Expected } \\
\text { Color }\end{array}$ & $\begin{array}{c}\text { Circles } \\
\text { Expected } \\
\text { Color }\end{array}$ & $\begin{array}{c}\text { Radial Lines } \\
\text { Expected } \\
\text { Color }\end{array}$ \\
\hline Cross-shaped stimuli, no fixation condition & $\begin{array}{l}\text { Long lines } \\
\text { Short lines }\end{array}$ & $\begin{array}{l}14 \\
11\end{array}$ & $\begin{array}{l}0 \\
1\end{array}$ & $\begin{array}{l}0 \\
2\end{array}$ & $\begin{array}{l}9 \\
6\end{array}$ & $\begin{array}{l}5 \\
8\end{array}$ \\
\hline Cross-shaped stimuli with fixation & $\begin{array}{l}\text { Long lines } \\
\text { Short lines }\end{array}$ & $\begin{array}{l}9 \\
9\end{array}$ & $\begin{array}{l}3 \\
4\end{array}$ & $\begin{array}{l}2 \\
1\end{array}$ & $\begin{array}{r}6 \\
10\end{array}$ & $\begin{array}{l}8 \\
4\end{array}$ \\
\hline Complex stimuli & $\begin{array}{l}\text { Radial lines } \\
\text { Circles }\end{array}$ & $\begin{array}{l}5 \\
6 \\
\end{array}$ & $\begin{array}{l}1 \\
8\end{array}$ & $\begin{array}{l}8 \\
0\end{array}$ & $\begin{array}{r}2 \\
12 \\
\end{array}$ & $\begin{array}{r}12 \\
2\end{array}$ \\
\hline
\end{tabular}

Note-As the only free choice responses produced by subjects were "green," "blue," "red," "pink," and "no color," frequencies of responses categorized as "no color," "circles expected color," and "radial lines expected color" are shown. The data of Subject I have been omitted for reasons given in the text. The significance levels of various distributions are quoted in the text.

\section{Discussion}

The aim of the second experiment was to test a model incorporating both orientation and fixation as a possible explanation of the effect observed in the tirst experiment.

The data replicate the finding of the first experiment and clearly shows that a stimuluscontingent complementary aftereffect was elicited by the circles and radial lines test stimuli. Some idea of the contidence with which subjects were able to report the effect can be gained by noting that two-thirds of the free choice responses are in agreement.

Taken as a whole, the data from the cross-shaped stimulus conditions do not suggest that any color aftereffect was elicited by them. Thus it seems that the effect is not capable of being explained simply by reference to fixation and orientation analyzers. However, there are particular points which do not support this general conclusion. The forced choice data show significantly more appropriate responses in the fixation conditions when analyzed subject by subject (tive subjects reported more appropriate colors in the fixation condition. no subject reported less: sign test, $\mathrm{p}=.03$ ). Also, the odd subject (subject 1) reported seeing the aftereffect colors in the appropriate areas initially for each pattern.

A follow-up study with this subject produced some interesting results. Despite an apparently equivalent adaptation period, no flipping was reported and, in testing. only colors appropriate to the orientation model were reported. This suggests that the flipping may have been caused by incidental factors during the original adaptation or testing procedure. During prolonged inspection of a test stimulus, the aftereffect colors are seen to fade. The fading times for this subject were measured. The colors on both cross-shaped stimuli faded in about $30 \mathrm{sec}$, but the aftereffect colors on the circles and radial lines test stimuli were reported to be relatively stable (not noticeably fading over $2 \mathrm{~min}$ ). Since this difference in persistence seems unlikely to be a function of the relative sizes of the visual fields involved, it seems that the effect for the cross-shaped test stimuli (presumably deriving solely from orientation and fixation) is very much weaker than the effect from concentric circles and radial lines (presumably deriving from a situation in which other influences may operate). This supports the conclusion that though orientation analyzer mechanisms might be involved. they cannot be the sole cause of the effect for this particular subject and, indeed, are unlikely to be even a major cause.

This conclusion applies even more strongly to the data of the remaining subjects. There is only a little evidence for the orientation and fixation model in that the fixation and nonfixation conditions for the forced choice situation differ significantly (see above). But the level of significance is of quite a different order from those of the main result $(.03$ as against .0003 and $.00016)$.

\section{GENERAL DISCUSSION}

For both experiments, a simple alternative explanation to the orientation model could be based on spatial frequency. That is, it could be suggested that the patterns caused color adaptation independently because of the different sizes of the elements of the different patterns. Leppmann (1973) demonstrated such an effect of differential color adaptation to different sized elements. In the present displays. the crucial sizes of the elements of the stimuli may be taken either to be those running parallel or those running orthogonally to the lines in the stimulus display. If the length of line elements parallel to the lines of the patterns are considered then. since any arc of a circle which approximates a straight line must be shorter than a radius of that circle. the predictions of this model are equivalent to those of the orientation model (i.e.. the cross-shaped stimuli should elicit both aftereffect colors, the long and short lines eliciting the radial and the circles 
eliciting the color aftereffect. respectively). Such predictions are not borne out by the data.

It the size analyzers are considered to operate orthogonally to the main lines of the display, then it would be predicted that the only colors seen on the cross-shaped stimuli will be the concentric circles aftereffect colors, because only here did the appropriate spatial frequency predominate. The radial lines stimulus contains, in the wedge-shaped sections between the radial lines, a large variety of spatial frequencies almost all of which are smaller than those found in the concentric circles stimulus. The problem about predicting the occurrence of only one of a pair of aftereffects is that the prediction could fail to be contirmed merely as the result of a shift of the subject's neutral point so that he did not notice the aftereffect. However, the difference between the mean spatial frequencies of the two patterns is about 2 octaves. Lovegrove and Over (1972) induced a spatial frequency-contingent color aftereffect using a much smaller difference between the spatial frequencies of the two inducing stimuli ( $11 / 2$ octaves). Yet they report data which show that the majority of their subjects gave $100 \%$ appropriate responses after only 5 or 10 min adaptation. The subjects were asked to respond with the judgments "red," "green," and "no color." This is comparable with the free choice condition in the present work; the forced choice condition could be much more confidently expected to produce evidence for an aftereffect. Thus a search of the forced choice data of the present work for evidence of a tendency to report only aftereffect colors appropriate to the concentric circles stimulus (on the cross-shaped stimuli) ought to be a strong test of the involvement of spatial frequency mechanism. Now for the two fixation conditions. respectively, 15 and 16 responses appropriate to the circles color aftereffect were elicited out of 28 responses for each condition (Table 3). Thus, over the total of 56 responses, there was no tendency for subjects to report only circles color aftereffects.

There now remains the question of interactions between orientation and spatial frequency effects. When both orientation and spatial frequency differences are present in visual stimuli, there is no evidence to suggest that either of the two feature-analyzing mechanisms will override the other. Teft and Clark (1968) had no difficulty in eliciting an orientation-contingent aftereffect, even when the difference between spatial frequencies of their adapting and test stimuli was sufficient, judging by the data of Lovegrove and Over (1972), to have set up a spatial frequency-contingent color aftereffect. Also, Leppman (1973) reports no difference in aftereffect when a straight line grating containing various spatial frequencies which elicited spatial frequencycontingent color aftereffects, in appropriate parts of the grating, was rotated through $90 \mathrm{deg}$. These two studies seem to us to demonstrate that orientation and spatial frequency analyzing mechanisms may be separately and independently adapted.

Thus, it seems reasonable to suppose that when these two mechanisms interact their effects are additive. That is, if the expected aftereffects contingent on orientation and spatial frequency conflict, then no aftereffect will be seen. In the second experiment here, the expected aftereffects conflict for the long lines of the cross-shaped stimuli. But each model predicts that the short lines will elicit the circles color aftereffect. Thus, if spatial frequency mechanisms were involved in this type of interaction, one would expect the short lines, where the two effects coincide, to elicit more appropriate responses. Testing the forced choice data for differences between the short lines, where the effects coincide, and long lines, where the effects contradict one another, would provide a sensitive test of the involvement of spatial frequency mechanisms. On the long lines, where the effects contradict one another, a neutral aftereffect would be expected and this would make more detectable the aftereffect hue on the short lines. In fact, there was a very slight tendency for the short lines to elicit more appropriate responses. Also, this tendency is stronger in the no fixation condition (Table 3), which favors the involvement of spatial frequency. mechanisms. However, there is very little evidence for the tendency (6 in 11 and 10 in 18) in either fixation condition. Thus there seems to be little evidence for the involvement of spatial frequency analyzers.

\section{CONCLUSIONS}

It seems reasonable, then, in the light of the available evidence, to suggest that although orientation analyzers may be involved, under certain circumstances, they are not the major cause of the effect in the concentric circles and radial lines displays. Neither can the effect be attributed to size analyzer mechanisms.

The most obvious difference between the two patterns is that one involves curved lines and the other straight lines. Riggs (1974a, b) has already proposed the notion of curvature analyzers. Such mechanisms would afford a useful explanatory concept here.

\section{REFERENCES}

Harris, C. C., \& Gibson, A. R. Is orientation-specitic color in human vision due to edge-detectors, after-images or dipoles"? Science, 1968, 164, 1506-1507.

Held, R., \& Shattuck. S. R. Color and edge sensitive channels in the human visual system. Tuning for orientation. Science. 1971. 174. 314-316.

LePPMANn. P. K. Spatial trequency dependent chromatic after effects. Nature. 1973, 242, 411-412. 
Lovegrove. W. J.. \& Over, R. Color adaptation of spatial frequency detectors in the human visual system. Science. 1972, 176. 541 .

Mc Collough, C. Color adaptation of edge-detectors in the human visual system. Science. 1965, 149. 1115-1116.

MACKAY. D. M.. \& MACKAY. V. Orientation sensitive after effects of dichoptically presented colour and form. Nature, 1973, 242. 477-479.

Maynew, J. E. W., \& Anstis, S. M. Movement after effects contingent on color. intensity and pattern. Perception \& Psychophysics. 1972, 12. 77-85.

MuRCh, G. M. Size judgments of McCollough after images. Journal of Experimental Psychology, 1969, 81. 46.

Murch, G. M. Binocular relationships in a size and color orientation specitic after effect. Journal of Experimental Psychology, 1972. 93. 30-34.
Stromeyer, C. F., \& MANsfield, R. J. W. Colored aftereffects produced with moving edges. Perception \& Psychophysics, 1970. 7, 108-114.

Riggs, L. A. Curvature as a feature of pattern vision. Science. 1974, 181, 1970. (a)

Riggs. L. A. Curvature detectors in human vision? Science. 1974. 184. 1199. (b)

TEFT, L. W.. \& ClaRK, F. T. The effects of stimulus density on orientation specitic after effects of color adaptation. Psychonomic Science, 1968, 11, 265.

(Received for publication November 1975; revision received February 1976.) 